\title{
Question 1 tobacco education expenditures in Massachusetts, USA
}

\author{
Michael E Begay, Stanton A Glantz
}

\begin{abstract}
Background-In 1992, voters in Massachusetts (United States) approved Question 1, a state ballot initiative, which raised the state excise tax to provide funds for tobacco education.

Objective-To examine Question 1 expenditures for tobacco-specific programmes in the 1994, 1995, 1996, and 1997 fiscal years.

Design-This study examined trends in Question 1 expenditures. Data were collected from the Massachusetts Department of Public Health and the Massachusetts Department of Revenue for the 1994, 1995,1996 , and 1997 fiscal years.
\end{abstract}

Main outcome measures - The amount of spending on tobacco-specific programmes.

Results-Excluding the 1994 fiscal year because the state allocated 18 months of new revenues, from the 1995 fiscal year to the projected 1997 fiscal year, the state will have spent $22 \%$ of Question 1 funds for tobacco-specific programmes. Question 1 expenditures for tobacco-specific programmes have declined by $15 \%$, whereas Question 1 expenditures for the other programmes decreased only $0.4 \%$.

Conclusions-The legislature has established a trend that has produced real reductions in Question 1 funding for tobacco education, which appears contrary to the mandate of the voters when they enacted Question 1 in 1992. These reductions undermine the effectiveness of tobacco-specific programmes that are an integral part of the Massachusetts Tobacco Control Programme. These results also highlight the fact that the initial compromises made after initiatives such as Question 1 are adopted have important long-term consequences for funding of tobacco control initiatives.

(Tobacco Control 1997;6:213-218)

Keywords: tobacco tax; education programmes; funding

\section{Introduction}

In 1992, a coalition of more than 200 organisations called the Massachusetts Coalition for a Healthy Future (MCHF), led by the American Cancer Society (ACS), successfully placed on the ballot and campaigned for the passage of Question 1, a state ballot initiative that raised the state tax on cigarettes by 25 cents per pack and on smokeless tobacco by $25 \%$ of its wholesale price to provide funds for tobacco education programmes. ${ }^{1-3}$ Question 1 was modelled after California's Proposition 99, which was enacted in 1988 and also raised the state tobacco tax to fund tobacco education, research, and medical services ${ }^{4-6}$ and dramatically accelerated the decline in tobacco consumption in California. ${ }^{7-10}$

Question 1 established the Health Protection Fund into which the new revenues would be placed $^{11}$; the new revenues were not designated as a part of the state general fund. The initiative advised the legislature to appropriate the new revenues for four purposes.

- Comprehensive school health education programmes, which incorporate information relating to the hazards of tobacco use

- Workplace-based and community smoking prevention and smoking cessation programmes, for tobacco-related public service advertising and for drug education programmes

- Community health centres and their programmes of prenatal and maternal care, which incorporate smoking cessation assistance and guidance regarding the harmful effects of smoking in fetal development

- Monitoring of morbidity and mortality from cancer and other tobacco-related diseases in the state.

Of these provisions, only the second one advises the state to develop and implement tobacco-specific programmes. It also contains a mandate for drug education. The other programmes are more limited in the amount of tobacco education and prevention services that are provided. Because of the state constitution, the initiative does not earmark the new revenues but advises the legislature to appropriate the funds for the above purposes. This situation has allowed the state to spend a large amount of Question 1 revenues on programmes that are not tobacco-specific.

\section{Methods}

We gathered information on Question 1 expenditures from documents provided by the Massachusetts Department of Public Health and Massachusetts Department of Revenue and material published by the Massachusetts Tobacco Control Programme. ${ }^{12}$

\section{Results}

TOBACCO-SPECIFIC PROGRAMMES

The Massachusetts Tobacco Control Program (MTCP) is the name for the state's tobacco education campaign, which is funded entirely by the Health Protection Fund. MTCP focuses on three major types of activity: (a) programme

Department of
Community Health
Studies, School of
Public Health and
Health Sciences,
University of
Massachusetts,
Amherst,
Massachusetts, USA
M E Begay
Institute for Health
Policy Studies,
Department of
Medicine, School of
Medicine, University
of California, San
Francisco, California,
USA
S A Glantz
Correspondence to:
Dr Michael E Begay, Box
30430, University of
Massachusetts, Amherst,
Massachusetts 01003-0430,
USA; email
begay@schoolph.umass.edu


Table 1 Total Health Protection Fund expenditures (in thousands of US\$) for tobacco-specific programmes, $1994-97$ fiscal years *

\begin{tabular}{|c|c|c|c|c|}
\hline Tobacco education and prevention & $1993-94$ & 1994-95 & $1995-96$ & 1996-97 \\
\hline Media campaign & 15349 & 14113 & 13160 & 11732 \\
\hline \multicolumn{5}{|l|}{ Statewide/regional initiatives } \\
\hline Quitline & 701 & 1135 & 1075 & 675 \\
\hline Dana Farber (Worksite) & 443 & 260 & 178 & 44 \\
\hline John Snow, Inc. (Clearinghouse) & 710 & 570 & 498 & 250 \\
\hline Education and training initiative (STAT) & 724 & 500 & 420 & 256 \\
\hline \multicolumn{5}{|l|}{ Education/training (University of } \\
\hline Massachusetts Medical Center) & 0 & 592 & 509 & 273 \\
\hline Cap. building/training & 264 & 549 & 550 & 508 \\
\hline Prevention centres & 2241 & 1510 & 1150 & 1022 \\
\hline Subtotal & 5083 & 5116 & 4380 & 3028 \\
\hline \multicolumn{5}{|l|}{ Research/evaluation/demonstration projects } \\
\hline Massachusetts Tobacco Survey & 718 & 0 & 0 & 0 \\
\hline Youth survey & 0 & 0 & 0 & \\
\hline Independent evaluation (Abt Associates) & 664 & 550 & 378 & 240 \\
\hline \multicolumn{5}{|l|}{ Behavioural risk factors (Northeast } \\
\hline Associates) & 48 & 50 & 75 & 75 \\
\hline Cancer registry & 495 & 0 & 0 & 0 \\
\hline Research and demonstration projects & 946 & 1555 & 1256 & 1199 \\
\hline Subtotal & 2871 & 2155 & 1709 & 1514 \\
\hline \multicolumn{5}{|l|}{ DPH administration/programme support } \\
\hline Administration & 690 & 386 & & \\
\hline Family health & 136 & 70 & & \\
\hline Tobacco staff & 331 & 161 & & \\
\hline Subtotal & 1157 & 617 & 781 & 906 \\
\hline \multicolumn{5}{|l|}{ Local community initiatives } \\
\hline Coalitions & 897 & 1355 & 1342 & 1197 \\
\hline Youth/leadership & 2770 & 3190 & 3255 & 2970 \\
\hline Populations at risk & 1611 & 2341 & 2443 & 2223 \\
\hline Smoking cessation programs & 910 & 3181 & 3202 & 2950 \\
\hline Boards of health & 4979 & 4945 & 5445 & 4884 \\
\hline Subtotal & 11167 & 15012 & 15687 & 14224 \\
\hline Total expenditures & 35627 & 37013 & 35717 & 31404 \\
\hline
\end{tabular}

${ }^{\star}$ Based on figures from documents provided by the Massachusetts Department of Public Health.

DPH $=$ Massachusetts Department of Public Health; STAT $=$ Stop Teenage Addiction to Tobacco.

services, such as counselling smokers who want to quit; (b) mass media campaigns to inform the public about the dangers of smoking and exposure to secondhand smoke; and (c) policy actions, such as encouraging communities to limit youth access to tobacco products. These activities are administered through the Massachusetts Department of Public Health (DPH) and are tobacco-specific (table 1). ${ }^{13}$ A large amount of money goes through the DPH to school health services programmes and school-based health centres. These school programmes are not tobaccospecific, but may incorporate tobacco education, prevention, and cessation activities into school health services, and are not included as tobacco-specific programmes but as "other programmes". ${ }^{13}$ The main goal of MTCP is to reduce tobacco use in Massachusetts by $50 \%$ between 1993 and 1999 .

OTHER PROGRAMMES

The initiative also contains provisions for other programmes that incorporate tobacco education and prevention services but are not tobacco-specific. These specified programmes consist of comprehensive school health, drug education, community health centres, monitoring morbidity and mortality from cancer, and maternal and child health. The initiative thus provides funding for comprehensive school health education programmes that incorporate information regarding the hazards of tobacco use. For example, the Massachusetts Health Protection Grants Initiative provides non-competitive, entitlement grants to school districts to provide financial and technical assistance to implement comprehensive school health education programmes; it uses a comprehensive pre-school to high school health education curriculum, which includes a variety of topics and strategies such as violence prevention, substance abuse prevention, student support services, and student health centres. The evaluation of this programme, ${ }^{14}$ however, found that health education content focusing on tobacco use prevention declines after the eighth grade (ages 13-14) and only half the students surveyed reported getting instruction on smoking cessation; less than half of all school districts (45\%) require tobacco prevention health education in the 10 th grade (ages 15-16) and only $52 \%$ of students reported learning ways to stop smoking.

The legislature allocated Question 1 funds for the Drug Awareness and Resistance Education programme (DARE), which uses police officers to provide comprehensive drug education but does not provide tobaccospecific services. DARE, although enjoying a strong political constituency, has been controversial because recent studies ${ }^{14}$ have questioned the effectiveness of the DARE programme.

The legislature allocated Question 1 funds to maternal and child health programmes such as WIC (Women, Infants, and Children's Nutrition Services), and the Healthy Start programme. Question 1 asked that these programmes include a tobacco prevention component, but they are not tobacco-specific programmes. The legislature also allocated Questions 1 funds to the Office of Health Statistics Analysis and for the operation of a cancer registry and occupational lung disease registry. This office collects data on mortality of tobacco-related disease. Morbidity data are also collected by the DPH.

\section{NON-APPROVED PROGRAMMES}

The legislature has allocated Question 1 funds for programmes that were not approved by the voters when they passed Question 1 in 1992, that is, the initiative does not contain language advising the legislature to fund these activities. These non-approved programmes primarily provide health services. This group of programmes include the AIDS prevention and treatment programme, substance abuse treatment, osteoporosis education and prevention services, and the early breast cancer detection and research programme. These non-tobacco education programmes do not have even nominal tobacco education elements. In the 1995-96 budget, the legislature allocated Question 1 funds for the fire education programme, SAFE, which is required to include information about the fire risks caused by careless cigarette smoking and to include the participation of local firefighters. It is not clear whether this programme contains any meaningful tobacco control component. 
Table 2 Total expenditures (in thousands of US\$) from Health Protection Fund and State General Fund for Question 1 programmes, $1994-97$ fiscal years*

\begin{tabular}{|c|c|c|c|c|c|}
\hline Approved Question 1 programmes & 1994 & 1995 & 1996 & 1997 & Total \\
\hline \multicolumn{6}{|l|}{ Tobacco-specific programmes } \\
\hline expenditures & 35627 & 37013 & 35717 & 31431 & 139788 \\
\hline Total HPF expenditures (\%) & 23 & 29 & 27 & 26 & 26 \\
\hline Change from 2nd to 4th FY (\%) & & & & -15 & \\
\hline State General Fund (SGF) expenditures & 0 & 0 & 0 & 0 & \\
\hline Subtotal HPF+SGF expenditures & 35627 & 37013 & 35717 & 31431 & 139788 \\
\hline HPF+SGF expenditures (\%) & 19 & 19 & 17 & 16 & \\
\hline \multicolumn{6}{|l|}{ Other programmes } \\
\hline HPF expenditures & 91616 & 67562 & 71248 & 66010 & 296436 \\
\hline Total HPF expenditures (\%) & 59 & 53 & 55 & 55 & 56 \\
\hline Change from 2 nd to 4 th FY (\%) & & & & -2 & \\
\hline SGF expenditures & 0 & 21915 & 22504 & 22491 & 66910 \\
\hline Subtotal HPF+SGF expenditures & 91616 & 89477 & 93752 & 88501 & 363346 \\
\hline HPF+SGF expenditures (\%) & 48 & 45 & 45 & 45 & 46 \\
\hline Change from 2nd to 4 th FY (\%) & & & & 3 & \\
\hline \multicolumn{6}{|l|}{ Non-approved programmes } \\
\hline HPF expenditures & 26950 & 22166 & 23145 & 23324 & 95585 \\
\hline Total HPF expenditures (\%) & 17 & 17 & 18 & 19 & 18 \\
\hline Change from 2nd to 4th FY (\%) & & & & 5 & \\
\hline SGF expenditures & 34736 & 51211 & 54128 & 54601 & 194676 \\
\hline Subtotal HPF+SGF expenditures & 61686 & 73377 & 77273 & 77925 & 290261 \\
\hline $\mathrm{HPF}+\mathrm{SGF}$ expenditures (\%) & 33 & 37 & 37 & 39 & 37 \\
\hline Change from 2nd to 4th FY (\%) & & & & 6 & \\
\hline \multicolumn{6}{|l|}{ Total HPF and SGF expenditures } \\
\hline HPF expenditures & 154193 & 126741 & 130110 & 120765 & 531809 \\
\hline Change from 2nd to 4th FY (\%) & & & & -5 & \\
\hline SGF expenditures & 34736 & 73126 & 76632 & 77092 & 261586 \\
\hline Change from 2 nd to 4 th FY (\%) & & & & 5 & \\
\hline Grand total expenditures (HPF+SGF) & 188929 & 199867 & 206742 & 197857 & 793395 \\
\hline Change from 2nd to 4th FY (\%) & & & & -1 & \\
\hline
\end{tabular}

${ }^{\star}$ Based on figures from documents provided by the Massachusetts Department of Public Health and the Massachusetts Department of Revenue.

$\mathrm{FY}=$ fiscal year

\section{Question 1 expenditures \\ 1994 Fiscal year}

After the passage of Question 1, the coalition was unprepared for the political battle to allocate the new revenues (interview with $\mathrm{Dr}$ Blake Cady, 26 July 1995). As a result, the DPH took the lead in developing a tobacco control programme. The Department of Revenue began collecting the Question 1 tobacco tax in January 1993, but the first legislation implementing Question 1 did not pass until May 1993, so the legislature had 18 months of new revenues to appropriate. In budget negotiations with the legislature and Governor William Weld's administration, the MCHF estimated the costs of an optimal antismoking programme to be $\$ 96$ million out of total of $\$ 176$ million in available Question 1 revenues. MCHF had hoped to place the $\$ 80$ million in unexpended Question 1 funds in reserve because revenues would decline in future years as smoking prevention and cessation programmes reduced the number of new smokers and helped existing smokers to quit. ${ }^{16}$ The coalition subsequently relinquished claims to the surplus because it feared the Weld administration would take all the funds for other purposes. ${ }^{16}$

The compromise had two major effects on the Massachusetts tobacco education campaign. First, it established the precedent for use of Question 1 funds for non-tobacco education purposes. Second, it established a de facto ceiling on the fraction of Question 1 monies that would be used for tobacco education and pre- vention programmes. Altogether, these effects, combined with the fact that the initial fiscal year allocation of Question 1 funds was based $\overrightarrow{0}$ on 18 months of tobacco tax accumulations, set the stage for declines in funding for tobacco education.

In the 1993-94 fiscal year, the state spent a total of $23 \%$ of Question 1 funds for 으 tobacco-specific programmes (table 2). The $\frac{\sigma}{3}$ state spent $77 \%$ of Question 1 funds for the other programmes (specified and nonapproved). Most of the tobacco-specific expenditures were for local community initiatives such as boards of health $\frac{7}{0}$ programmes, youth/leadership programmes, and the anti-smoking media campaign. A total $N$ of $\$ 15.3$ million was spent on the anti-smoking $N$ media campaign. This is only the second large, N publicly paid, anti-smoking media campaign in $\sigma$ the United States, other than California's Proposition 99 anti-smoking media campaign. Although the first fiscal year was unusual $\stackrel{?}{+}$ because the state allocated 18 months of 0 revenues, the initial establishment of priorities $\bar{P}$ and values in the first year of funding was sig- $\stackrel{\square}{\stackrel{D}{\circ}}$ nificant for determining the size and nature of $\stackrel{\otimes}{\propto}$ the tobacco-specific programmes in subse- $\overline{0}$ quent fiscal years.

\section{Fiscal year}

The state spent $29 \%$ of Question 1 funds on tobacco-specific programmes; other programmes spent $71 \%$ of the funds. Question 1 expenditures for tobacco-specific programmes grew by almost $4 \%$ in comparison with the 
previous fiscal year. Although Question 1 expenditures for the other programmes decreased by $24 \%$, the legislature more than made up for this reduction using state general funds for the other programmes, so that total spending (Question 1 funds plus general funds) for these programmes actually increased by $6 \%$. Most ( $81 \%$ ) of these general funds went to AIDS prevention and treatment, substance abuse treatment, and WIC. This pattern continued for subsequent fiscal years. Overall, the first two fiscal years show the relatively low priority given by the legislature to funding specific tobacco control efforts as evidenced by the initial split in the 1994 fiscal year, and subsequent willingness to actually increase funding of other programmes by using general fund revenues, while restricting tobacco control programmes to declining revenues in the Health Protection Fund.

In the 1995 fiscal year, the state spent more Question 1 funding for local community initiatives, which accounts for almost all of the $4 \%$ increase in total spending for tobacco-specific programmes. As a result, there were major cutbacks in tobacco education evaluation and research. For example, the Massachusetts Tobacco Survey (MTS) of adults and youth had its funding severely reduced. The amount spent in the 1993-94 fiscal year was $\$ 718000$ but was $\$ 150000$ in subsequent years. The original purpose of the MTS was two-fold: (a) to provide a baseline against which to assess the impact of the Massachusetts Tobacco Control Programme; and (b) to inform the continuing design of interventions aimed at helping smokers quit, preventing teens from starting to smoke, and reducing risks associated with exposure to environmental tobacco smoke. Although a smaller study of tobacco use among adults continued, it was not as comprehensive and thorough as the first MTS and also lacked a youth survey. Although this type of research might not convince legislators to support tobacco control, it may help public health groups to mobilise public opinion to lobby legislators and the governor.

1996 Fiscal year

In the $1995-96$ budget, the state spent $27 \%$ of Question 1 funds for tobacco-specific programmes. The other programmes continued to spend a large share $(72 \%)$ of Question 1 funds. There was an almost $4 \%$ decrease in Question 1 expenditures for tobacco-specific programmes compared with the 1995 fiscal year. In comparison, Question 1 expenditures for the other programmes increased by $5 \%$ and total expenditures (Question 1 funds and general funds) for these programmes increased by $5 \%$. Total Question 1 spending increased by a modest $2 \%$.

1997 Fiscal year

In the projected 1996-97 fiscal year budget, Question 1 funding for all programmes declined. However, tobacco-specific programmes took the brunt of the Question 1 funding reductions compared with the other programmes. Tobacco education funding decreased $12 \%$ compared with the 1996 funding, whereas the other programmes' expenditures decreased only by $5 \%$. As in past years, this reduction for the other programmes was partially offset by state general funds. As a result, total spending (Question 1 funds and state general funds) for the other programmes decreased only by a modest $3 \%$.

\section{SUMMARY}

Excluding the first fiscal year (because the state spent 18 months of new tobacco tax revenue), between 1994-95 and the projected 1996-97 fiscal years, the state will have spent a total of $22 \%$ of Question 1 funds for tobacco-specific programmes. Over this same period, the state reduced Question 1 expenditures for tobacco-specific programmes by $15 \%$. In addition, the state will have spent a total of $74 \%$ of Question 1 funds for other programmes which provide little, if any, tobacco education services. Based on the projected 1996-97 budget, Question 1 expenditures for the other programmes will have declined by $0.4 \%$ since the 1994-1995 fiscal year. However, total funding (Question 1 funds and general funds) for these programmes will have increased by $2 \%$ (table 2).

\section{Discussion}

There are three significant findings. First, the state has used Question 1 funds for purposes not approved by voters. Second, the legislature has given relatively low priority to funding specific tobacco control efforts, as evidenced by the initial split in funding between approved and non-approved programmes; and the subsequent willingness to actually increase funding of other programmes by using general fund revenues, while restricting tobacco control programmes to declining revenues in the Health Protection Fund. Finally, the initial establishment of priorities in the first year of funding for determining the size and nature of the tobacco-specific programmes is significant.

At the same time that the tobacco industry used claims in its campaign against Question 1 that the tobacco tax revenues raised by Question 1 would not be used to reduce tobacco use, it was actively-and successfully-using its political influence to see that funds allocated to tobacco education and research in California's Proposition 99 were diverted to medical services. ${ }^{591718}$ As the Boston Globe predicted shortly after the voters enacted Question $1,^{19}$ the same pattern of diversion of funds away from tobacco prevention activities that occurred in California has occurred in Massachusetts.

The tobacco-specific programmes funded by Question 1 have made some progress in meeting the goals established by its authors. The MTCP has been successful in reducing tobacco sales by $18 \%$ from 1992 to the first half of $1995^{1320}$ and has reduced exposure of workers to secondhand tobacco smoke. Total cigarette consumption in Massachusetts was well below the trend established in the eight years before Question 1 passed. ${ }^{1021}$ However, despite the mandate of the voters and the 
progress of the programme, the legislature has not consistently followed the intent of the voters in implementing Question 1.

Question 1 expenditures show that legislators have not looked favourably on tobacco-specific programmes when appropriating Question 1 funds and general funds. These programmes have carried the brunt of the reductions in Question 1 funds. Total expenditures for the other specified programmes have increased by $3 \%$ and non-approved programmes by $6 \%$ between the 1995 and 1997 fiscal years.

The pattern of Question 1 expenditures in Massachusetts is similar to what had occurred in California. ${ }^{51718}$ Public health groups in California also agreed to a compromise which allowed the legislature and governor to divert Proposition 99 funds from tobacco education to medical services beginning in the 1989-90 budget. However, these groups changed their policy after seeing how the diversions were undermining the effectiveness of the tobacco education campaign. In 1994, six years after passage of Proposition 99, the American Lung Association, the American Cancer Society, and Americans for Nonsmokers' Rights sued the state. In their series of cases filed in Superior Court, the health groups argued that the diversions were illegal because they were contrary to the intent of the initiative. The court agreed with the plaintiffs and ordered the state to revert the unlawfully appropriated funds to tobacco education and research programmes. (There have been a series of appeals and the case is still before the State Supreme Court in California.) After a protracted and public political battle, the California legislature enacted legislation to appropriate the funds consistent with Proposition 99 for the 1996-97 fiscal year. Because the Massachusetts constitution only permits initiatives to advise the legislature on appropriations, however, public health advocates in Massachusetts cannot resort to legal action to restore funding of tobacco control programmes financed by Question 1.

Public health advocates played a major role in the decision that allowed the legislature to appropriate Question 1 funds for non-tobacco education programmes. After the initiative passed, the initial budget compromise made by MCHF established the precedent for this failure to use Question 1 funds consistently for tobacco education. In fact, after the 1994-95 state budget was passed, senator Thomas $F$ Birmingham (Democrat from Chelsea), the chair of the senate ways and means committee, said in response to public health advocates' criticism, "If Cady [chair of the MCHF] and the other smoking cessation and prevention advocates were unhappy how the money has been used, they should have said so in 1993, when the basic structure for distributing the cigarette tax was established." 16

An important lesson is the need to mobilise public opinion, which helps in lobbying the legislature and governor to follow the voters' mandate. Public health advocates appear to have recognised the power of grass-roots lobbying. They succeeded in mobilising public 공 opinion in response to Governor Weld's proposal to divert $\$ 60$ million in Question 1 funds from tobacco education to finance an income tax cut of $\$ 500$ million. ${ }^{22-24}$ This diversion, similar to those implemented by California governor Pete Wilson, would have eliminated the state tobacco education campaign. MCHF, led by Blake Cady and the American Cancer Society, used a public opinion poll which showed that $82 \%$ of voters surveyed supported spending all Question 1 funds on anti-smoking programmes and that diversion of funds away from tobacco control would damage Governor Weld's then-planned bid to run for the US Senate. ${ }^{23} 24$

While the ACS and the coalition successfully of fought the governor's proposal to divert $\$ 60$ million in Question 1 funds, it remains to be $\vec{\omega}$ seen if the ACS and other public health advo- 을 cates will apply the political pressure necessary on the legislature and governor to fulfill the original voters' mandate of Question 1, or if the pattern of using Question 1 funds for other programmes will continue. Unlike what happened in California when the public health groups sued the state to enforce the voters' mandate in Proposition 99, Question 1 did not earmark funds, which may make it very difficult for public health groups in Massachusetts to resort to legal action to restore funding to tobacco-specific programmes.

Another lesson public health groups should consider in contemplating an initiative similar to Proposition 99 and Question 1 is the political problem created by the revenue windfall in the first fiscal year. In Massachusetts, the 1994 fiscal year was extraordinary in that policy makers had to appropriate 18 months of new revenue. This windfall created an opportunity for the state to allocate funds to the other programmes. Thus, initiative writers in other states should include language on how to handle the first year windfall (until implementing legislation is enacted). They may consider allocating these excess funds over the first three to five years of the tobacco control campaign.

It would appear that the first step in restoring the integrity of the tobacco control programmes financed by Question 1 will be to recover from the effects of the initial compromises made in 1993, which established the precedent of using Question 1 funds for purposes other than genuine tobacco control. The lessons of both Massachusetts and California indicate that advocates who support increasing the tobacco tax to fund tobacco education must plan to continue the battle they fought when they secured passage of the tax to see that the money is spent on real tobacco control, as promised in the campaign to enact the initiative. Advocates in other states considering similar ballot initiatives need to plan an ongoing effort to see that the initiative is implemented as the voters intended. It is particularly important to avoid early compromises (when money appears plentiful immediately after the initiative begins generating funds, but before appropriating legislation is passed) that establish precedents that can have 
long-term adverse effects on the financing of the tobacco control programme. Public health advocates seeking to increase tobacco taxes as a way of funding tobacco prevention activities must be prepared for an ongoing battle to see that these programmes are funded in accordance with the voters' initiative in the first place.

This work was supported in part by the Association of Schools of Public Health/Centers for Disease Control and Prevention/Agency for Toxic Substances and Disease Registry Prevention/Agency for Toxic Substances and Disease Registry Massachusetts Faculty Research Grant (1-03238), American Massachusetts Faculty Research Grant (1-03238), American National Cancer Institute (CA-61021).

1 Heiser P, Begay M. The campaign to raise the tobacco tax in Massachusetts. Amherst, Massachusetts: School of Public Health and Health Sciences, University of Massachusetts, Amherst, October 1995.

2 Heiser $P$, Begay $M$. The campaign to raise the tobacco tax in Massachusetts. Am $\mathscr{f}$ Public Health 1996;87:968-73.

$3 \mathrm{Koh} \mathrm{H}$. An analysis of the successful 1992 Massachusetts tobacco tax initiative. Tobacco Control 1996;5:220-5.

4 Bal DG, Kiser KW, Felten PG, Mozar HN, Niemeyer D. Reducing tobacco consumption in California: development of a statewide anti-tobacco use campaign. $¥ A M A$ 1990;264:1570-4

5 Begay $M$, Traynor $M$, Glantz $S$. The tobacco industry in state politics and funding tobacco education in California. Am $\mathcal{F}$ Public Health 1993;83:1214 21

6 Traynor M, Glantz S. The development and passage of Proposition 99. F Health Politics Policy Law 1996;21:544 85.

7 Glantz SA. Changes in cigarette consumption, prices, and tobacco industry revenues associated with California's Proposition 99. Tobacco Control 1993;2:311-14

8 Pierce JP, Evans N, Farkas AJ, et al. Tobacco use in California: an evaluation of the tobacco control program, 1989-1993. La an evaluation of the tobacco control program, 1989-1993. La Jolla,

9 Monardi F, Balbach E, Aguinaga S, Glantz S. Shifting allegiances: tobacco industry expenditures in California, fanuary 1995-March 1996. San Francisco, California: Institute for Health Policy Studies, University of California, San Francisco, April 1996.

10 US Centers for Disease Control and Prevention. Cigarette smoking before and after an antismoking campaign: Massachusetts, 1990-1996. MMWR. 1996;45:966-70.

11 Commonwealth of Massachusetts. Initiative petition of William C Allard and Others. Boston: Office of the Secretary. liam C Allard and Others. Boston:

12 Massachusetts Tobacco Control Program. Massachusetts tobacco control project directory (draft). Boston: Massachusetts Department of Public Health, 1994.

$13 \mathrm{Abt}$ Associates. Independent evaluation of the Massachusetts tobacco control program: second annual report, fiscal year 1996. Boston: Massachusetts Department of Public Health, April 1996.

14 Rosenbaum D, Flewelling R, Bailey S, Ringwalt C, Wilkinson $D$. Cops in the classroom: a longitudinal evaluation of Drug Abuse Resistance Education (DARE). 7 Res Crime Delinquency 1994;31:3-31.

15 Robinson D, Strunin L. Toward a healthier Massachusetts for children: the first year evaluation of the health protection grant initiative. Boston: Massachusetts Department of Education, December 1994.

16 Murphy SP. Smoking opponents feel misled on tax: lawmakers unfairly diverted funds from cigarette sales to other programs, activists say. Boston Globe $1994 \mathrm{Sep} 25$.

17 Begay M, Traynor M, Glantz SA. Extinguishing Proposition 99: political expenditures by the tobacco industry in California politics in 1991-1992. San Francisco: Institute for Health Policy Studies, University of California at San Francisco, September 1992.

18 Aguinaga S, Macdonald H, Traynor M, Begay M, Glantz S. Undermining popular government: tobacco industry political Undermining popular government: tobacco industry political expenditures in California, 1993-1994. San Francisco: Institute for Health Policy Studies

19 McGrory B. Tobacco industry assault expected. Boston Globe 1992 Nov 8.

20 Abt Associates. Independent evaluation of the Massachusetts tobacco control program, executive summary: first annual report, fiscal year 1994. Boston: Massachusetts Department of Public Health, February 1995.

21 Glantz S. The ledger of tobacco control (letter). $f A M A$ 1996;276:871-2.

22 Phillips F. Cigarette tax is fund source in Weld's plan. Boston Globe 1995 Nov 9.

23 Phillips F. Doctor says Weld broke vow on tobacco. Boston Globe 1995 Nov 10.

24 Anon. Overcome by smoke (editorial). Boston Globe 1995 Nov 10. 